\title{
The Future of Psychoses as Seen from the History of its Evolution
}

\author{
John Torous • Matcheri Keshavan
}

Published online: 6 April 2014

(C) Springer International Publishing AG 2014

\begin{abstract}
Reflecting on the history of psychoses reveals several trends in psychiatry's approach to this difficult disease. The field initially took a symptom-based categorical approach in the $18^{\text {th }}$ to the early $19^{\text {th }}$ century; in the late $19^{\text {th }}$ century, Kraepelin unified diverse categories into the unitary concept of dementia praecox, and separated it from manic depressive insanity. While this distinction has persisted ever since, the last 5 decades witnessed a focus on operationalizing symptomatic criteria continuing into the current Diagnostic and Statistical manual (DSM) classification. While reliability has improved somewhat, the question of validity of the psychosis diagnosis remains elusive. Recent approaches attempt to investigate disease dimensions across diagnoses, characterize heritable biomarkers, and identify translational domains of psychopathology across molecular, cellular, circuit, and behavioral units of analyses. Such efforts may help deconstruct current symptom-based phenotypes and allow reconstruction of disease constructs that may better map to etiology, pathophysiology and treatment response. Studying the history of the concept of psychosis affords a unique vantage point to better understand the challenges associated with this current thinking and how such may guide today's work in creating tomorrow's new definition of psychoses, probably better grounded in neuroscience.
\end{abstract}

Keywords History · Psychosis · Phenomenology · Nosology $\cdot$ Kraepelin $\cdot$ Future $\cdot$ Schizophrenia $\cdot$ Bipolar disorder · DSM

\footnotetext{
J. Torous $(\bowtie) \cdot$ M. Keshavan

Harvard Longwood Psychiatry Residency Training Program, 330

Brookline Avenue, Boston, MA 02215, USA

e-mail: jtorous@bidmc.harvad.edu

J. Torous

Department of Psychiatry, Beth Israel Deaconess Medical Center, Harvard Medical School, Boston, MA, USA
}

\section{Introduction}

Despite over a century of research, the nature and nosology of psychotic illnesses remains unclear. While reliability of diagnoses improved with the advent of the diagnostic and statistical manual in the 1950s, especially with DSM-III [1], the latest revision DSM-V [2] continues to show relatively modest inter-rater clinician reliability for diagnosing psychosis in adults, with kappa of approximately 0.65 [3•]. Even with the release of DSM-V in 2013, diagnoses are still based only on symptoms and history, and there are no confirmatory or diagnostic radiological, laboratories, or psychometric tests for schizophrenia-related disorders [4]. This state of affairs has persisted over the past century, despite impressive advances in the neuroscientific basis of behavior in health and disease. In this context, the words of recent American Psychiatric Association president Dr. Lieberman ring true: "It is useful to revisit and reflect on the past to understand better not just where we are now, but where we are going" [5]. This paper aims to examine the history of psychosis and demonstrate how the thinking and debates of the past may shape and predict future directions. We review history of psychosis under three epochs: first, the era of symptom-based splitters in the $18^{\text {th }}$ and $19^{\text {th }}$ centuries; second, the efforts to unify the diverse categories into unitary disease models, led by Kraepelin; and third, the focus on reliability leading to operational diagnostic criteria - and finally, the current quest for validity and efforts toward biologically based classification (Fig. 1).

\section{From Antiquity to the $19^{\text {th }}$ Century: The Era of Splitters}

Descriptions of psychotic symptoms such as delusions, hallucinations, and bizarre behavior date back to antiquity [6], being referred to in the cuneiform tablets of ancient Mesopotamia during approximately the third millennium $\mathrm{BC}$, in 
Symptom-based types
Symptom-and course based types
Dimensional continuum and categories
Categories based on translational domains and categories based on etiology/ pathophysiology
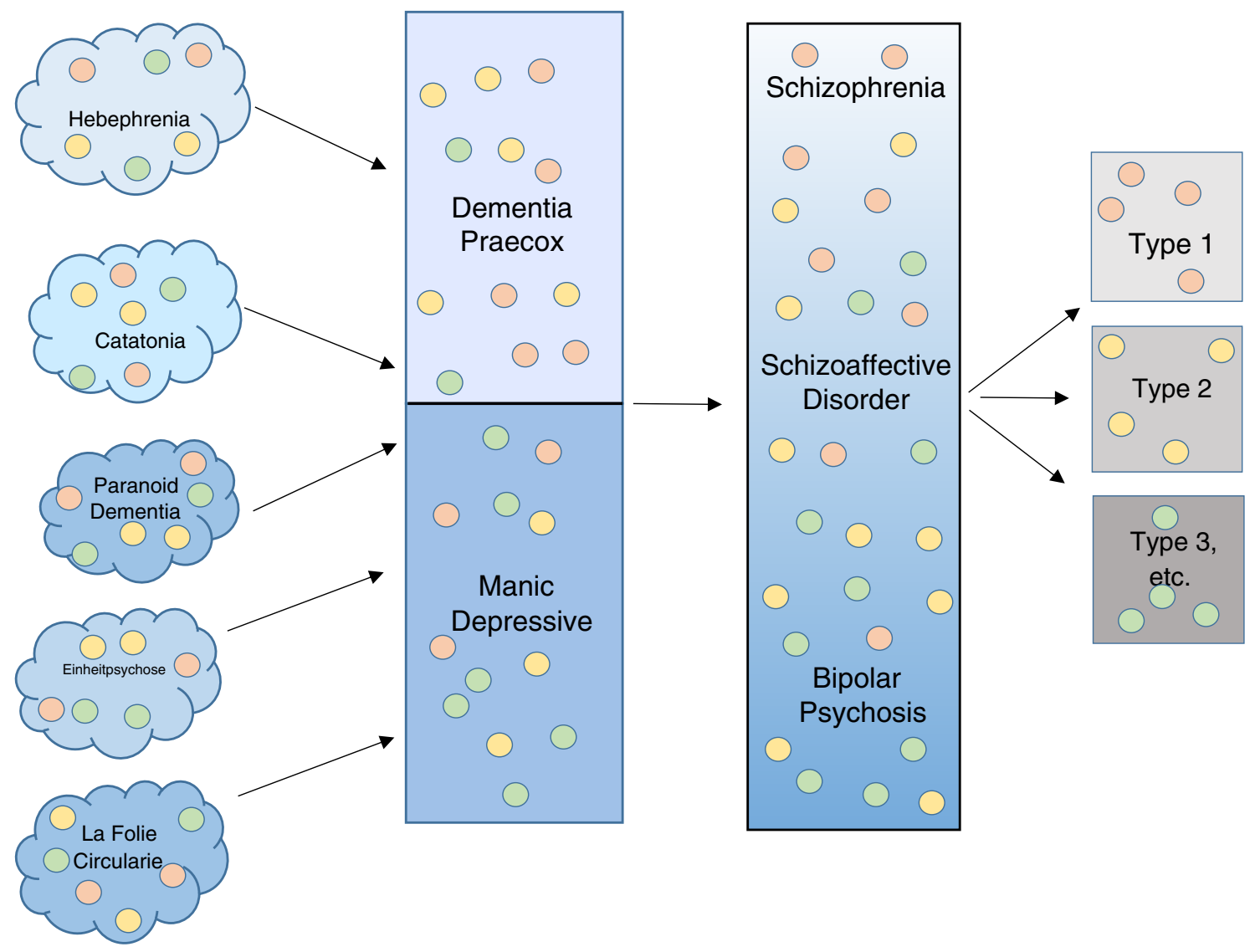

18 th century.

$19^{\text {th }}$ cent.

$20^{\text {th }}$ cent.

$21^{\text {st }}$ cent.

Fig. 1 A broad schematic overview of the evolution of theories of psychosis through time

writings in Indian medicine during approximately the $5^{\text {th }}$ century $\mathrm{BC}$, and in the writings of Herodotus in ancient Greece during approximately the $5^{\text {th }}$ century BC. The subsequent millennia, especially the Middle Ages, led to psychotic disorders moving away from the province of medicine to that of religion; in medieval Europe for example, psychotic symptoms were considered as spirit possession or divine visitation, and treated as such. The term psychosis emerged in the psychiatric literature around 1845 and originally represented a disease state that impacted the person as a whole, mind and body [7]. Feuchtersleben, the founder of the term psychosis, wrote that he believed psychoses were compound conditions that required one "to trace the causality existing between the disease of the mind and body" [8]. Given Feuchtersleben's broad definition, competing theories of psychosis quickly emerged in the literature. Some of these theories have been forgotten with time, such as Heinrich Neumann's approach claiming, "there is only one form of mental illness, that is insanity, which does not have different forms, but different stages" [9]. However, during the $19^{\text {th }}$ century, enduring descriptions of psychosis were also put forward, such as hebephrenia and catatonia, introduced by Hecker in 1871 and Kahlbaum in 1874, respectively. Greisinger claimed that mental diseases were secondary disorders to brain diseases [10], and described in 1861 what we may today consider chronic schizophrenia. La Folie Circularie, translated from French as circular insanity and today considered the earliest literature on bipolar disorder, was described in 1851 by Jean-Pierre Falret. 
With so many competing categories of psychoses, some proposed that each symptom should perhaps be considered a disease entity itself [10], while at the other extreme, the (einheitpsychose) unitary psychosis school of thought claimed that there is actually only one form of psychosis and that its varied manifestations are due to unrelated individual and personal characteristics of patients.

\section{Disease Models in Neuropsychiatry: Kraepelin, and Bleuler, the Great Unifiers}

In light of these numerous, confusing, and often contradictory definitions of psychosis, the field initially sought tangible truths in the emerging knowledge of brain pathology. This approach to assemble symptoms and signs to derive syndrome and disease definitions dates back to the $17^{\text {th }}$ century, when physicians such as Thomas Sydenham and Thomas Willis began describing disease entities correlating with pathology [11]. Starting in the mid $19^{\text {th }}$ century, early successes in localization of brain lesions were theorized to perhaps explain psychosis. This was an era of exciting discoveries, including Broca describing aphasia in 1861, Meynert localizing motor and sensory regions of the brain in 1867, Wernicke outlining his speech center in 1874, Pick describing the roles of frontal lobes in dementia in 1906, and Alzheimer reporting dementia associated with plaques and tangles in 1907. These tangible lesions underlying disease were also applied to psychosis, with Wernicke in 1885 writing his Textbook of Diseases of the Brain and in 1900 describing "the psychic reflex arc," in which he hypothesized that mental illness was caused by interruptions in continuity of association pathways [12]. Psychiatrists such as Nissel asserted, "in all psychoses of whatever type, there are always positive cortical findings" [13]. But such cortical findings could not always be identified. The most promising results transformed into the dementias of Pick and Alzheimer or more obscure findings such as Heinrich Neumann discovery of hypermetamorphosis, excess reaction to visual stimuli, that became incorporated into the pathology of Klüver-Bucy syndrome [14]. As these scientific undertakings were not translating into pragmatic theories or explanations of psychosis; the task was to become the work of another psychiatrist and the beginning of the modern notion of psychosis.

In light of early failures of localization of brain lesions to explain the complex nature of psychotic symptoms, Emil Kraepelin sought to merge pathological anatomy, clinical symptomology, and etiology into a more unified model of psychosis [15]. Kraepelin introduced a nosology capable of capturing the broad range of previously divided psychosis into two broad categories, either dementia praecox or manicdepressive insanity. Briefly, in dementia praecox, an organic defect was claimed as the basis of illness, leading to a progressive and deteriorating condition that today may be labeled as schizophrenia, while in manic depressive insanity the etiology was stated as unknown, had a more variable course and often a better prognosis, and is labeled today as bipolar disorder. Longitudinal observation and clinical course formed the basis of Kraepelin's nosology. With this system, Kraepelin was the first psychiatrist to introduce a pragmatic, clinically, and prognostically oriented nosology based on quantitative and naturalistic research methods [11].

However, Kraepelin's concept of dementia praecox as a distinct disease entity met with two roadblocks. First, unlike Alzheimer's disease and general paresis of the insane, no "lesions" were to be found in idiopathic psychoses. It was even stated that schizophrenia was the 'graveyard of neuropathologists' because of a failure to identify clear hallmarks of brain pathology [16]. Second, even Kraeplin himself admitted that it was difficult, if not at times impossible, to always separate dementia praecox from manic depressive insanity, and he wrote in 1910, "it is indisputable today that, despite honest efforts, we are still unable to categorize quite a vast number of cases within the frame of one of the known forms in the system" [17]. Kraepelin's hope that the work of neuroanatomical investigations would resolve such conflict and eventually support and verify his nosology was unfulfilled, despite the efforts of prominent scientists such as Nissl and Alzheimer [18], and this lack of validating criteria created the opportunity for new formulations. Kraepelin himself lamented that "no one will regret it more than I if dementia praecox temporarily becomes too large a category," and realized that "change will continue until more knowledge ... has been reached" [19].

Indeed, Eugene Bleuler (1911), who is credited with renaming dementia praecox as schizophrenia (split-mind), suggested that this may not be one disease, but instead a "group of schizophrenias". He additionally argued that the essence of schizophrenia was not delusions and hallucinations, which he regarded as "accessory" symptoms, and that instead the "fundamental" symptoms of schizophrenia were disintegration ("splitting") of psychic functions, leading to loosening of association, blunt or incongruous affect, ambivalence, and autism (often known as Bleuler's 4 As) [20]. He thus considerably broadened the concept of schizophrenia.

\section{Jaspers and Schneider, Phenomenology and Diagnostic Reliability}

Around the same time, Jaspers' phenomenological method first appeared and was seen as a response to the need to increase validity of psychotic symptoms that Kraeplelin's nosology could not provide. Jaspers explained "only objective symptoms offer certainty; they alone form the basis for scientific study, whereas subjective symptoms, though we cannot easily do without them for our preliminary assessments, are 
considered quite unreliable" [21]. Burgy argues that the strength of Jasper's introduction of phenomenology was its attention to the immediate psychotic experience and on the form of the psychotic experience. By focusing on the form of the experience, Jaspers avoided the question of validity of the symptoms [22]. At the time of this work in 1912, Jaspers saw the role of neuropathology in psychiatry as useful only in metaphor and not clinical practice.

Jaspers' focus on phenomenology was continued by the German psychiatrist Kurt Schneider (1959) [23], whose work has come to perhaps define psychosis more than any other single influence in recent times. Schneider is best known for proposing 'first rank symptoms in schizophrenia,' such as auditory hallucination, delusions, thought insertion, and thoughts broadcasting, symptoms that were relatively easy to define and that became core elements in diagnosing schizophrenia. Interestingly, these criteria were more widely applied in Europe, while the broader Bleuler criteria were more popular in the US. This led to psychiatrists from across continents to widely vary in how they define and diagnose the same disorder. This stark lack of reliability was instrumental in increasing the field's focus on developing operational diagnostic criteria such as the Feighner criteria [24], research diagnostic criteria [25], and eventually the DSM-III criteria for schizophrenia [1]. However, while reliability of diagnoses improved somewhat with the focus on careful cataloguing of symptoms and course of illness by Kraepelin and later $20^{\text {th }}$ century psychiatrists, the vexing question of validity of diagnosis continues to challenge the field today.

\section{Validity, Dimensional Deconstruction and Quest for Etiopathological Types}

What may be seen from the foregoing discussion is that the history of psychosis classification has witnessed a veritable tug of war between lumpers: those who favor unitary or spectrum concepts of broad diagnostic categories; and splitters: those who favor distinct categories. The first wave of splitters used a symptom-based categorical approach; Kraepelin used disease models available to him at the time to construct a combination of cross-sectional and longitudinal phenotypic data to derive a unitary disease concept. The subsequent century of psychiatric nosologists, despite Kraepelin's own reservations, did relatively little to challenge this concept.

Over time, several "inconvenient truths" emerged that did not neatly fit the Kraepelinian divide. Current psychosis categories, such as schizophrenia, schizoaffective and psychotic bipolar disorders, do not tell us with any clarity as to which patients might do better with what treatments, leading to the widely prevalent practice of polypharmacy. There is considerable overlap in symptoms [26], neurobiology [27], genetics [28], and treatment response, as well as outcome characteristics [29], across these disorders. This led to the creation of the confusing concept of schizoaffective disorder, which unfortunately continues with us even in the latest iteration of DSM and International Classification of Diseases (ICD). These overlaps across symptom-based diagnoses have also made it difficult to develop diagnostic tests in psychiatry [30 $]$ other than those used to rule out medical illnesses (e.g. thyroid tests to rule out hypothyroidism as a cause of psychotic disorders). Early efforts to subclassify schizophrenia based on neurobiology [31, 32] unfortunately received insufficient attention and remain to be validated.

Two trends in recent decades offer promise to drive the field towards new directions by broadening our understanding of the nature of psychotic disorders. The first is our growing understanding of the dimensional nature of psychiatric symptoms. Thus, patients with schizophrenia, in addition to psychosis and negative symptoms, also have variable increases in depressive, motor, anxiety and cognitive symptoms; these dimensions do not obey DSM boundaries, and overlap greatly between psychotic, affective, developmental and personality disorders. At least some of such dimensions, such as anxiety and positive or negative salience, may be more easily mapped onto neurophysiological domains. The second trend is that research in recent years has led to a spate of new observations on the neurobiology and etiology of the psychotic disorders spectrum [33••], which possesses the potential to motivate a fresh effort to develop a neuroscience-informed nosology. Some of the observed biological alterations (e.g., abnormal event related potentials), which may be trait-related, heritable, present in unaffected relatives, and co-segregate with illness in families, are termed endophenotypes [34]. Endophenotypes may serve as potential footholds from symptom-based phenotypes to the underlying genotype. Elucidation of heritable biomarkers may allow deconstruction of psychosis and related dimensions agnostic to phenotypic diagnoses across translational domains from behaviors to molecules. In line with this thinking, Insel and Cuthbert of the National Institute of Mental Health (NIMH) recently proposed, "a new framework, the Research Domain Criteria (RDoC) of organizing information relevant to psychopathology based on dimensions of observable behavior and neurobiological measures...from genes to neural circuits to behaviors" [35]. In a manner, this amounts to a new approach to splitting- dimensional deconstruction of disease. Such cross-cutting bio-behavioral RDoC data can then be used to predict treatment response and develop targeted interventions, similar to what is already standard practice in oncology and renal disease. For example, psychosis associated with glutamate-related genes might respond to 
glutamate modulators, while those with susceptible calcium channel genes might respond to a calcium channel antagonist, regardless of the symptom-based subtyping of the psychotic disorder [36].

\section{Conclusion}

In summary, there is concern that psychiatry may not have adapted and evolved its thinking on psychosis as rapidly as might have been possible. While outside the scope of this paper, it is interesting to compare what the last decade has brought to other fields of medicine such as oncology and cardiology. In such a light, perhaps psychiatry has ascribed undue influence to its historical figures, many presented in this paper, when determining how to best approach and proceed with such a difficult disease as psychosis. However, it has been said that the future is like a corridor into which we can see only by the light coming from behind (ascribed to Edward Weyer). That light is especially important today, as psychiatry may now be approaching an era where there is an effort to reclassify mental illness, and especially psychosis, by pathophysiological processes much as Kraepelin sought. Now with nearly 100 years of scientific progress and efforts since Kraepelin's work, the challenge is whether the state of our current work on genetics, biomarkers, intermediate phenotypes, imaging, neuropsychological, and the neuropathological foundations of mental illness will provide the basis for a new, neuroscience-based nosology.

\section{Compliance with Ethics Guidelines}

Conflict of Interest John Torous and Matcheri Keshavan declare they have no conflicts of interest.

Human and Animal Rights and Informed Consent This article does not contain any studies with human or animal subjects performed by the author.

\section{References}

Papers of particular interest, published recently, have been highlighted as:

- Of importance

-• Of major importance

1. Diagnostic and statistical manual of mental disorders DSM-III. New York: American Psychiatric Publishing; 1980.

2. Diagnostic and statistical manual of mental disorders DSM-V. New York: American Psychiatric Publishing; 2013.

3. Narrow WE, Clarke DE, Kuramoto SJ, et al. DSM-5 field trials in the United States and Canada, Part III: development and reliability testing of a cross-cutting symptom assessment for DSM-5. Am J Psychiatry. 2013;170(1):71-82. doi:10. 1176/appi.ajp.2012.12071000. This is an important paper examining reliability of psychiatric diagnoses using data from DSM field trials.

4. Bhati MT. Defining psychosis: the evolution of DSM-5 schizophrenia spectrum disorders. Curr Psychiatry Rep. 2013;15(11):409. doi: 10.1007/s11920-013-0409-9.

5. Lieberman J. Change and opportunity: psychiatry in age of reform and enlightenment in psychiatric news. 2013. http://psychnews. psychiatryonline.org/newsArticle. aspx? articleid=1734097. Accessed 15 Sept 2013.

6. Jeste DV, del Carmen R, Lohr JB, Wyatt RJ. Did schizophrenia exist before the eighteenth century? Compr Psychiatry. 1985;26(6): 493-503.

7. Bürgy M. The origin of the concept of psychosis: Canstatt 1841. Psychopathology. 2012;45(2):133-4. doi:10.1159/000330257.

8. Feuchtersleben E. The principles of medical psychology - Ernst Feuchtersleben (Freiherr von) - Google Books; 1847.

9. Neuman H. Lehrbuch der psychiatrice. In: Berrios GE, Porter R, editors. A History of clinical psychiatry: the origin and history of psychiatric disorders. 1st ed. London: Athlone Press; 1999. p. 321.

10. Berrios GE, Beer D. Unitary psychosis concept. In: Berrios GE, Porter R, editors. A history of clinical psychiatry: the origin and history of psychiatric disorders. 1st ed. London: Athlone Press; 1999. p. 313-35.

11. Ackerknecht EH. A short history of medicine. Baltimore: Johns Hopkins; 1982.

12. Lanczik MH, Beckman H, Keil G. Wernicke. In: Berrios GE, Porter $\mathrm{R}$, editors. A history of clinical psychiatry: the origin and history of psychiatric disorders. 1st ed. London: Athlone Press; 1999. p. 30212.

13. Beer MD. Psychosis: a history of the concept. Compr Psychiatry. 1996;37(4):273-91. doi:10.1016/S0010-440X(96)90007-3.

14. Danek A. "Hypermetamorphosis." Heinrich Neumann's (1814 1884) [legacy]. Nervenarzt. 2007.

15. Hoff P. Kraepelin. In: Berrios GE, Porter R, editors. A history of clinical psychiatry: the origin and history of psychiatric disorders. 1st ed. London: Athlone Press; 1999. p. 261-79.

16. Plum F. Prospects for research on schizophrenia. 3. Neurophysiology. Neuropathological findings. Neurosci Res Program Bull. 1972;10(4):384-8.

17. Trede K, Salvatore P, Baethge C, Gerhard A, Maggini C, Baldessarini RJ. Manic-depressive illness: evolution in Kraepelin's textbook, 1883-1926. Harvard Review of Psychiatry. 2005;13(3):155-78. doi:10.1080/10673220500174833.

18. Jablensky A. The conflict of the nosologists: views on schizophrenia and manic-depressive illness in the early part of the 20th century. Schizophr Res. 1999;39(2):95-100. doi:10.1016/S09209964(99)00106-1.

19. Berrios GE, Hauser R. Kraepelin. In: Berrios GE, Porter R, editors. A history of clinical psychiatry: the origin and history of psychiatric disorders. 1st ed. London: Athlone Press; 1999. p. 280-301.

20. Bleuler E. Dementia Praecox, or the group of Schizophrenias, 1911. Translated by J Zinkin: International University Press, New York; 1950.

21. Jaspers $\mathrm{K}$. The phenomenological approach in psychopathology. $\mathrm{Br}$ J Psychiatry. 1968;114(516):1313-23. doi:10.1192/bjp.114.516. 1313.

22. Bürgy M. The concept of psychosis: historical and phenomenological aspects; 2008:1200-1210. doi:10.1093/schbul/sbm136.

23. Schneider K. Translated by Hamilton, MW. Clinical psychopathology. New York: Grune and Stratto; 1959.

24. Feighner JP, Robins E, Guze SB, Woodruff RA, Winokur G, Munoz R. Diagnostic criteria for use in psychiatric research. Arch Gen Psychiatry. 1972;26(1):57-63.

25. Spitzer RL, Endicott J, Robins E. Research diagnostic criteria: rationale and reliability. Arch Gen Psychiatry. 1978;35(6):773-82. 
26. Keshavan MS, Morris DW, Sweeney JA, et al. A dimensional approach to the psychosis spectrum between bipolar disorder and schizophrenia: the Schizo-Bipolar Scale. Schizophr Res. 2011;133(1-3):250-4. doi:10.1016/j.schres.2011.09.005.

27. Rimol LM, Hartberg CB, Nesvåg R, et al. Cortical thickness and subcortical volumes in schizophrenia and bipolar disorder. Biol Psychiatry. 2010;68(1):41-50. doi:10.1016/j.biopsych.2010.03. 036.

28. International Schizophrenia Consortium, Purcell SM, Wray NR, et al. Common polygenic variation contributes to risk of schizophrenia and bipolar disorder. Nature. 2009;460(7256):748-52. doi: 10.1038/nature08185.

29. Ivleva EI, Morris DW, Moates AF, Suppes T, Thaker GK, Tamminga CA. Genetics and intermediate phenotypes of the schizophrenia-bipolar disorder boundary. Neurosci Biobehav Rev. 2010;34(6):897-921. doi:10.1016/j.neubiorev.2009.11.022.

30. Kapur S, Phillips AG, Insel TR. Why has it taken so long for biological psychiatry to develop clinical tests and what to do about it? Mol Psychiatry. 2012;17(12):1174-9. doi:10. 1038/mp.2012.105. This is an important paper, as it explains the opportunity and need for psychiatry to focus on identifying biologically homogenous subtypes that cut across phenotypic diagnosis as a means to sidestep the difficult prospect of discovering biological gold standard definitions of current mental illnesses.

31. Crow TJ. The two-syndrome concept: origins and current status. Schizophr Bull. 1985;11(3):471-86.

32. van Praag HM. Kraepelin, biological psychiatry, and beyond. Eur Arch Psychiatry Clin Neurosci. 2008;258 Suppl 2:29-32. doi:10. 1007/s00406-008-2006-1.

33.• Insel TR. Rethinking schizophrenia. Nature. 2010. This is an important paper, as it explains how schizophrenia may be thought of a neurodevelopmental disorder in which psychoses is a late manifestation.

34. Gottesman II, Gould TD. The endophenotype concept in psychiatry: etymology and strategic intentions. Am J Psychiatry. 2003.

35. Insel TR, Cuthbert BN. Endophenotypes: bridging genomic complexity and disorder heterogeneity. Biol Psychiatry. 2009;66(11): 988-9. doi:10.1016/j.biopsych.2009.10.008.

36. Keshavan MS. DSM-5 and incremental progress in psychiatric nosology. Asian J Psychiatr. 2013;6(2):97-8. doi:10.1016/j.ajp. 2013.02.002. 